\title{
Creative identity theft: issues for artists in collaborative online environments
}

\author{
Gregory Sporton \\ Director, Visualisation Research Unit, Birmingham City University \\ School of Art, Birmingham Institute of Art \& Design \\ Margaret Street, BirminghamB3 3BX, United Kingdom \\ gregory.sporton@bcu.ac.uk
}

\begin{abstract}
This paper discusses the qualities of online activity in relation to what is 'new' in 'new media', and examines both the continued use of the technologies by artists to simply redress long standing disputes with the distribution models and editorial practices of 'old media' and the tensions created by encounters with the characteristics of the Internet as a new space for art. It then seeks to identify the features of new technologies that distinguish them from 'old media', principally the opportunities for interaction in real time, for collaboration, of skill sharing, of a wider audience that encounters work for reasons other than the contemplation of artistic work and the nature of proprietary technologies in themselves. These latter have rarely been developed specifically for artists, and often reflect the values and aims of the companies that generate them, presenting ethical and creative problems for artists who use them. The paper draws on research at the Visualisation Research Unit (VRU) at the School of Art, Birmingham City University, and its collaboration with Eastside Projects, a new gallery located in Birmingham, on the Arts Council funded project 'EP:VV' (Eastside Projects: Virtual \& Visualized).
\end{abstract}

New media art. Internet, Second Life. Digital technology.

\section{INTRODUCTION}

As a category of art practice, 'New Media' is as slippery a term as any other. Determining whether or not something might fit into the domain is often decided by the supporting technology (Paul, 2003). As Popper shows, the association of artists with new technologies is scarcely new (Popper, 1992). At the dawn of the age of electronic art, Popper firmly connected the emergent art practices with other moments in history when artists sought to associate or rebel against prevailing technological forces and the social revolutions they often prefigured or enabled. Thus, simply dealing with new technologies in itself seems hardly a 'new' thing for artists to do. For Paul, the sober difficulties of presenting 'new media' are located in the nature of the technologies. Is the work produced by digital signal processing? (Paul in Grau, 2006). If it is, then it surely qualifies as part of the genre. In this case, I would dispute the attribution, mostly because the newness of 'new media' does not appear to be located there, at least not entirely. Essentially, 'new media' work exists at the point when it encounters the 'new media' environment. Individual technologies have their effect, and closed system networking can have its moments, but 'new media' implies both new substance to make with and a new means of communicating the results. For me, this makes the Internet the appropriate channel for 'new media' activity in art. It remains perfectly possible to formulate the concept another way, but it is in the Internet that that the potential and difficulties lie, and this is where I want to begin. This, it would seem to me, would also qualify as one of the most difficult to spheres in which to practice art that we have, and at the same time apparently the most accessible. It is a paradox of the Internet that it should at once present itself as both the most difficult and easiest environments for art activity, requiring either complicated technology skills or simply the capacity to mash-up sources together in the name of creativity. In its current iteration it simultaneously endangers old forms and enables new models of art practice. Most of all, it threatens to redefine creativity as a universal value, flattening out the achievements of all those who would see themselves as such into having only a few keystrokes between them. We are past the point where this should be seen as benefit, and a discussion of this is somewhat overdue.

A further key distinction between 'new' and 'old' media is to qualify this use of the Internet. Much is made of the precipitous drop in the cost of production of 'old' media through advances and efficiency in the technologies required. This has a 
parallel in the capacity of the Internet to overcome old problems for artists seeking an audience for their work by new methods of distribution. But it is not enough for artists to simply carry on a dispute with the 'old' media systems to justify their work as new media. Having reduced video production costs to domestic modesty, becoming one's own editor in the process through the mastery of Final Cut Pro, then uploading the result to NetFlix or YouTube appears hardly to qualify as a 'new' media experience. This seems very like the old one, only with the costs stripped out and the editorial processes of broadcasting done away with, for the chance to compete for a global public's attention against cats attacking printers and Korean boys lipsyncing their favourite song on a webcam. For 'new media', the work needs to include an understanding of the environment and characteristics of the Internet as a space, and to use those as more than a means of wish-fulfilment, but to engage a public in the new way offered by the media. The Internet does not offer the solace of stasis. It is a dynamic environment that rewards interactivity and shuns the individual no matter how accomplished they may be. This essay is about what why artists struggle to come to terms with these features, and about what this tells about the future of 'new media' and the place of art within it.

\section{THE MUSIC EXPERIENCE}

One of the most significant challenges to the development of a 'new media' art has been the question of ownership and its relationship to authority and authorship in online environments. Whilst this has been broadly true in relation to all areas of what we have come to call the 'cultural industries', the issue here is about how this differs in the visual arts context, and places into question the fine artist's conception of themselves and their relationship and influence on the work they seek to call their own. The corresponding problems in other areas of cultural production, music for example, are more focussed on the legal rights of an artist to be rewarded for their work (often in reality a record company), or breaches of copyright through unauthorised distribution of music that reflect or damage existing business models (Mason, 2008). These are worthy of observation in directing us to the behaviours of consumers and the enthusiasm which has greeted the opportunity to have access to cultural products without the costs that had come to be accepted in the $20^{\text {th }}$ century, but fall short of addressing the art-specific problem, given the complexities of the economic and social distribution processes that apply there. They also fail to address the creative and philosophical problem that arises when creative production moves from the individual or locatable individual or group and becomes a distributed activity.
There is general consensus that these problems are partly of the creative industries own making: the lack of innovation in the e-commerce of the music industry and its structural inflexibility has caused great economic problems for the record companies faced now with the threat of extinction by file sharing and download culture (Lessig, 2004, Lanier, 2010, Mason, 2008). Disagreement emerges about the impact of the record companies' mistakes and the merits of a download culture. The artists themselves have responded with a resurgence of live performance, turning a decadesold economic model of money-making in music on its head. It is clear that the argument of the music industry executives (and a few performers) that these new models of consumption of music undermine creativity or investment in artists carry little weight with their customers, forced as they were into alternative methods of accessing music by the companies that now seek to persuade them to stop it.

The tensions in this sector of the creative industries are largely about management and business models, though Lanier (2010) takes significant exception to the impact the download culture has had on creative music making. The issues for creative artists in these fields coalesce around the relationship of production with the legal process and financial structures that determine or support them. They rarely deal with the nature of creativity itself, or the conventional assumptions of generators of creative work about their creative status as much as their legal one. Their focus is fixed on the 'monetising' of creativity, and the Web becomes a new environment for this process, a challenge not always met with either enthusiasm or imagination. From this emerges a reconceptualising of the Internet as a creative place: in the minds of those Lanier (2010) calls 'cybernetic totalists' the endpoint of its development is the migration of human consciousness into a vast web of self-generating perpetuity. The tension between two vast ideas are counterposed in this kind of analysis. Creativity, thought of as a definitively positive, life affirming force, is opposed to commercialism and its negative connotations of exploitation and profit. We will return to how business has come to think of the Internet and how it seeks to respond to the challenge it presents (through creativity, of course), but this forms merely the headline part of the problem, given that this wrangling is about money, not its relationship to creativity except as it affects rights.

Whilst there is plenty to be learned by the art community from the complexities of the Web as simultaneously creative and commercial space, and plenty of overlap in the lessons to be drawn about copyright and intellectual property, there is a further dimension of complexity that challenges the 
fine artist. For a long time before the emergence of the Internet, fine art practice was deliberately problematising issues around the ownership of the creative process. From Duchamps through Manzoni, the appropriation of everyday life, whether through ready-mades or the environment, has been a theme thoroughly worked over by artists to the point where this problematic became conventional. Fine art practice has regularly opened new questions about what constitutes production, authorship and completion as part of its evolution. The difference is that in its earlier incarnations this process occurred within the confines of the art world itself, with mere gestures to broader cultural experience. The Internet is less a respecter of such arrangements for reasons that will be discussed below, and as such turns the conceptual and philosophical disputes of the past into a practical reality with important consequences. Appropriation, it turns out, is one of the features of the Internet experience, and it is artists who taught the technologists this particular trick. But also, the possibility for artists to be genuinely original in their thinking, a quality we have come to expect from our experience of $20^{\text {th }}$ century art, is more difficult once the domain becomes dominated by mass collaboration.

\section{THE PARAMETERS OF THE ENVIRONMENT}

The challenge for artists is how to operate in the Internet environment without abandoning their sense of self. This is especially true where the artist is seeking to exploit the characteristics of the Internet beyond its attractiveness as a billboard, by invoking its potential for sharing and developing an art work through the participation of a user community. The importance of finding new ways to respond is a considerable conceptual and creative challenge, whose solutions will be a response to the ability of the Internet to be as wantonly destructive as its claims to be a creative space. It is at least as much about the nature of the technology and the value system it imposes on those who use it as it is about basic creative questions.

At this point, it is worth identifying what some of the characteristics of the online experience are, and how they change the way artists work in that space. One of the themes now redolent in the literature of business, located in its fear of the Internet and its capacity to make long-standing business models redundant overnight, has been the use of mass collaboration. For Leadbetter (2009), this is a positive, democratising force that enables any large company to better use both its internal resources and its customers to produce more satisfying responses to the products they produce. Leadbetter goes further to talk in terms of this mass collaborative movement having great potential to force social change, though it appears unclear about how and why disembodied and unowned ideas, like the flavour of a Wikipedia entry, will or ought to be privileged over individuation, vision or leadership. This distributed model of social consciousness is a key feature of new business, using the always on social technology framework to reinforce corporate messages through association and assimilation. Surowiecki (2004) cites the story of the how crowds can come to a consensus on the weight of a bull, suggesting that cooperation of this kind, releasing the resources from hierarchical imbalances, can come up with the right answer under most conditions. It is this style of identification of distribution of resources that runs contrary to the individual concerns of the artist. Can an artist wait until a consensus has been reached before making a contribution? Should they? And what are the risks of going ahead of the crowd? The Internet, it appears, is happy to absorb the creativity of artists, but less happy to acknowledge the personal contribution unless it can be subsumed into a larger proposition about culture and creativity in general. In this account, artists on the Internet are offering resources to it only for the purpose of adding to its evolution into consciousness. This is an unacceptable elision to most artists, whose identity is determined by the work they create.

The nature of anonymity on the Internet encourages robust exchanges (think 'flame wars' or 'trolling'). As Naughton (1999) points out, these tell us more about how humans will behave under the cloak of secrecy than about the harmful nature of the technology itself. Having suggested that the technology is also culturally driven, it would seem that anonymity and pseudonymity of this type has caught on as part of our cultural experience. Cyberbullying, the use of the very ubiquitous technology that has been so heavily promoted, turned to a means of persecution seems an obvious result of the cloak of secrecy. In 2006, when uploading a film to YouTube, at the VRU we were astonished by the response we had (Sporton, 2008), both in viewing figures and 'critical' reception. Part of the experience of art on the Internet is to know that people without any interest at all in art will have an opinion about it, and are quite likely to express it given they can do so without fear of reprisal. This is part of the dynamic of the web, but it also becomes factored in to the construction process for new media art. The reach of an artist's work can be far wider than might attend a gallery in a remote part of the country, or the world for that matter. It may also be far less specialised, not buying into the culture of art, but seeing it in their own terms and thus having their own views. Informed or not, the Internet flattens out their responses, using the false claim of democratisation to claim them as legitimate as any 
seasoned critic. It can also last a long time, graffiti posted on a digital wall that does not atrophy, with potential to be revisited over and over.

\section{THE ARTIST PREPARES}

There is no question about the need for artists to stake a claim to the Internet as public space. Fuelled as it is by the transformative technology of the day, it is surely the role of the artist to lay open its nature most clearly, and by participating in it, give evidence of its value. Its novelty is both an opportunity and a problem. The difficulty for the artist is how to respond to this 'new' environment, given that it often runs counter to the training and practice of fine art, with its overwhelming emphasis on art as individual expression. If, for artists, working in the web-space is to produce more than a passing billboard to refer visitors to some 'real' art in an art gallery, they must come to grips with the nature of the Internet and its character. The matter is complicated by the traditional assumptions about who their audience is, and what sustains the interest of gallery visitors. After all, regardless of whether the demographic of those who would choose to visit the physical location of a work and those who would surf for it online is similar, we know the behaviour of those who access the Internet differs from their everyday experience. The anonymity afforded to the visitor in the online space, and the substance of the technology, makes the encounter significantly different, before factoring in the responses of those who have no interest in the arts at all coming across work in the randomising process the Web is particularly good at. So, in the first place there is a new audience, both in method and purpose, potentially far larger than those traditionally relied upon to visit physical space, and this moves to a further problem.

The difficulties artists encounter when their will and vision is not the main source of content or interest clearly creates a struggle about their relevance to the work that is produced; often bruising encounters with technologists and user communities result. This is amplified in the kind of work it is currently possible to make in cyberspace. As Lanier (2010) points out, the connectivity of all these computers locks technological solutions in, sometimes long before they are mature enough, or alternative methods have had sufficient exploration before plumping for a determinate solution. His example, the MIDI technology that has determined the character of synthesised musical notes, is a compelling one. By proceeding down this route so long ago, the type of sound has an unfaltering value, even where the quality of choice in other areas of a composition is markedly different. In this, commercial interests do seem to be culpable. The force with which they have exhorted consumers to invest in proprietary technological solutions has assisted them to both lock-in technological solutions for future planning and fund development of the next generation of related technologies knowing the standards have been inflicted on an uninformed public who has unwittingly endorsed them through the purchase of technology products in the first place. This is because, for technologists at least, interoperability is a far more useful characteristic than fidelity, helping to bring into being the 'noosphere' fantasised by the more ridiculous end of cyber-speculators, and therefore a price worth paying, regardless of the potential of alternative systems.

This is where much of the difficulty for artists really begins to strike home. In an environment where artists are often dependent on the products of technologists to provide the means of production and the basic parameters for their creative ideas, they are also prone to the values of those technologists. The Internet works the way it does because of a belief system, adopted early on, that sharing and access are more important than property or stability. Whilst this looks harmless enough, its effects can be debilitating for those who have a justifiable claim to protection for their production, especially where they conduct themselves online without the backing of major technology producing corporations, or the means of defending themselves from having their work appropriated. The conflict of interest begins to look like old-fashioned Marxism (or cyber-Maoism in Lanier's terms), where the arrangements for participation require the apparently free-willed accession of rights to others to appropriate or reconfigure as they wish. Acceding control to potential users to develop or reconfigure the data is fraught with issues from security to censorship, and often strikes directly at the intentions of artists seeking to engage in this way, and yet this is part of the online experience. For artists who identify themselves with their work as personal statement, this becomes a critical tension. Their identity as creators is subject to appropriation by the demand to offer resources for free for the greater good of reifying a notion of what the Internet might become.

\section{THE EP:VV}

I have discussed a number of features of working in an online space, and the troubles artists can have with them. Many of these have been drawn from my own direct experience. In 2009, Eastside Projects, an artist-led space based in Birmingham, made an agreement with my lab and an artist to produce an online project. The development of an online gallery that reflects and resembles the physical space at an avant-garde gallery like Eastside and consistent with the content produced 
in it has thrown up important questions about the way in which arts experiences can be reproduced in the online space. The issues over how to create and curate art works that use the nature of the technologies, or represent them without simply creating 3D copies have led to difficult issues about why artists create work and who it is for in the online context. As a group, the artists and researchers involved wanted to use the project to learn more about how to operate in this area, and were interested in what issues might arise. The ambition was to produce a viable alternative gallery, accessible by a wide community, that had resonances with our own physical space without being a direct copy of it. Given the talents of the people involved, it has been a surprising failure. We simply failed to come to grips with many of this issues I have discussed above. In closing, I want to turn now to just one decision that was fateful for the project.

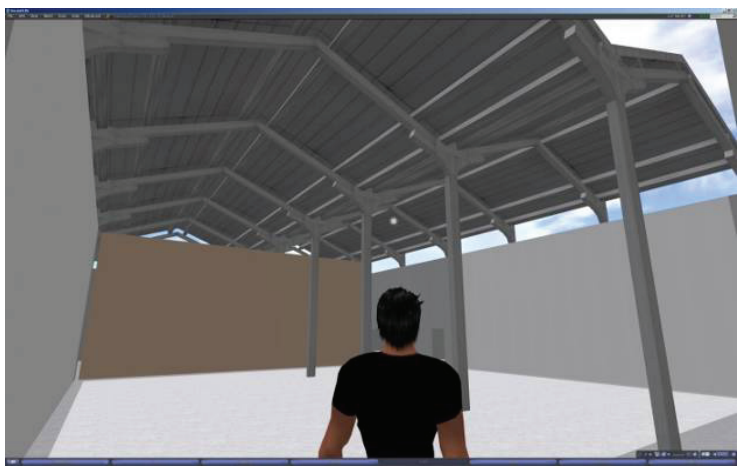

One of the first major mistakes we made as a group was to persist with Second Life. We knew from the outset that it was not desirable to even start there in the first place, and we investigated a number of alternatives. The difficulty was that both the lead artist and the lead 3D designer knew Second Life well, and felt they could handle its inadequacies for the task until we decided on an alternative. We would then be able to port what we had into a new environment, and work on from there.

In practice, this was almost impossible. In the first place, it became quite evident that the lead artist and designer were very comfortable in this space. Given that working with new technological paradigms can be fraught with error and demand many late nights, as the project went on it became increasingly difficult to make that transition. It began to be less viable with every element we placed within the space. We became victims of technological lock-in, of the kind discussed above, where the investment of time and money made it more difficult to migrate to a better system because of the proprietary nature of the system we were working in.

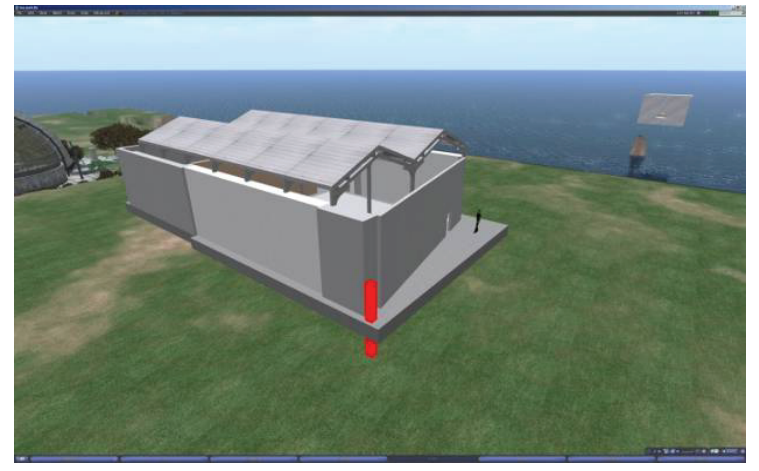

The artists who were involved as creators, meanwhile, absolutely hated Second Life. They kept observing the extent to which freedom was something to be paid for, that the rules of construction were oriented to encourage the purchase of new faculties or third-party plug-ins. They felt that despite the potential of a space in Second Life, the ultimate owners, Linden Labs, were not about to hand anything over that was useful or interesting, and were, theoretically at least, the ultimate owners of anything the artists produced. The potential of visitors was seen by some as a positive opportunity to engage with a new audience, and by others as a fearsome encounter with porn-addled imbeciles with nothing much to add. The result was an unhelpful stand-off, with sound arguments on both sides as to why we could not move forward. The nature of the technological platform we had chosen determined the fate of our project almost immediately we had started.

\section{CONCLUSION}

I have discussed the definition and nature of new media art, and touched on the challenges for artists in this field. In particular, I have focussed on the experience of the Internet as being the configuring and defining environment for new media art, and attempted a brief survey of its functions and properties, how they manifest for other creatives and what the issues may prove to be for art practice. Most of all, I have sought to encourage artistic engagement with the Internet. Creative practice there seems poised on a precipice. Should we abandon the field to those who are content with mash-ups and rehashes of pre-Internet culture, or should artists be seeking ways to present new creative experiences to that vast number of users across the globe with access to technology? What can artists offer by way of a critique of its current line of development? The engagement of artists in new media of this kind will be predicated on changes to how they think and what they expect from displaying their art work and creating with this new material another way of seeing the framework of the Internet. This is true for any new paradigm, 
that there will be philosophical and practical changes that will reconfigure the manner in which we participate. For the Internet, art that exploits the environment to tell its own story can emerge where the artists themselves choose to master the technological framework as part of a new craft practice.

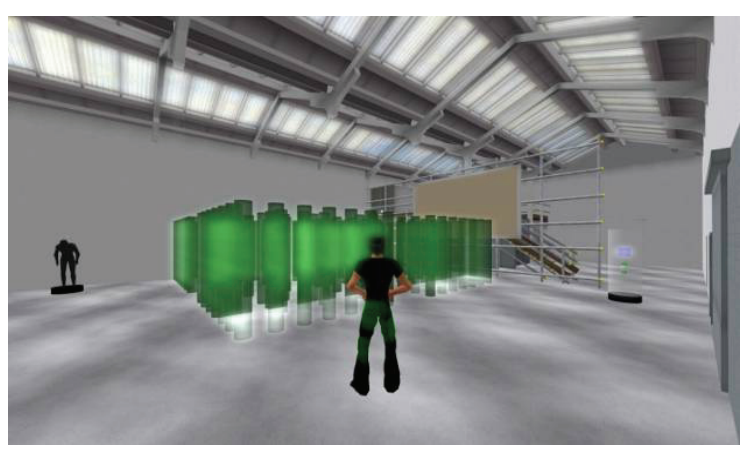

\section{REFERENCES}

Davis, E. (1998) TechGnosis: Myth, Magi \& Mysticism in the Age of Information.

Dixon, S.(2007) Digital Performance: A History of New Media in Theatre, Dance, Performance Art \& Installation. MIT Press, Cambridge, MA.

Grau, O., ed. (2007) MediaArtHistories. MIT Press, Cambridge, MA.
Hartley, J., ed. (2005) Creative Industries.

Blackwell Publishing, Malden, MA.

Lanier, J. (2010) You are not a Gadget. Allen Lane, New York.

Leadbetter, C. (2009) We-Think. Profile Books, London.

Lessig, L. (2004) Free Culture. Penguin Books, New York.

Mason, M. (2008) The Pirate's Dilemma. Allen Lane, New York.

Mezrich, B. (2009). Accidental Billionairres. William Heinemann, London.

Naughton, J. (1999) A Brief History of the Future. Weidenfield \& Nicholson, London.

Paul, C. (2003) Digital Art. Thames \& Hudson, London.

Popper, F. (1992) Art in the Electronic Age. Thames \& Hudson, London.

Siegel, L. (2009) Against the Machine. Spiegel \&Grau, New York.

Sporton, G. (2008) In White, C., Modes of Spectating. Intellect Books, Bristol.

Tapscott, D. and Williams, A.D. (2008) Wikinomics: How Mass Collaboration Changes Everything. Atlantic Books, London. 